\title{
TENDÊNCIAS NO RELACIONAMENTO HUMANO NA ÁREA DA SAÚDE
}

\author{
Janayna Poiato Braga ${ }^{1}$, Ana Maria Dyniewicz² Ozana de Campos $^{3}$
}

\begin{abstract}
RESUMO: Tendo em vista as grandes mudanças decorrentes neste último século quanto à evolução das empresas perante a globalização, as organizações de saúde que primeiramente tinham por objetivo executar ações de promoção e prevenção de saúde, atualmente desenvolvem-se como uma organização multifacetada, com diversos profissionais, em diferentes áreas, para a efetivação do atendimento à saúde. Este artigo tem por finalidade oferecer reflexões acerca de relacionamento humano em ambiente hospitalar, imprescindível para a realização de sua atividade fim. Em administração surge a necessidade de desenvolver um novo estilo, voltado para o diálogo e o trabalho em equipe, pois as pessoas, com suas características individuais, necessidades sociais, materiais e psicológicas, influenciam comportamentos com reflexos diretos no ambiente de trabalho.
\end{abstract}

PALAVRAS-CHAVE: Relacionamento humano; Saúde; Enfermagem.

\section{TRENDS IN HUMAN RELATIONSHIP IN THE HEALTH AREA}

\begin{abstract}
In view of the significant changes in the last century in relation to the evolution of companies facing globalization, health organizations that ultimately objectified to carry out actions for health promotion and prevention, are currently developed as multifaceted organizations, with several professionals, in different areas, to further health care delivery. This article aims to offer reflections on human relationship in hospital settings, essential for the accomplishment of the target-activity. In management, it is deemed necessary to develop a new style, oriented to dialogue and teamwork, once people, with their idiosyncrasies, social, material and psychological needs influence behaviors with straightforward consequences in the work environment.
\end{abstract}

KEYWORDS: Human relationship; Health; Nursing.

\section{TENDENCIAS EN LA RELACIÓN HUMANA EN EL ÁREA DE LA SALUD}

RESUMEN: considerando los grandes cambios de este último siglo en lo referente a la evolución de las compañías y la globalización, las organizaciones de salud, que, antes, tenían el objetivo de ejecutar la acción de la promoción y la prevención de la salud, se desarrollan, actualmente, como organizaciones múltiplas, con profesionales diversos, en diversas áreas, para las acciones de la atención a la salud. Este artículo tiene el propósito de ofrecer reflexiones referentes a la relación humana en el hospital, ambiente esencial para la realización de su actividad. En la administración, se desarrolla un nuevo estilo, dirigido hacia el diálogo y el trabajo en equipo, pues las necesidades de la gente, con sus características individuales, sociales, materiales y psicológicas, tienen reflejos en el ambiente del trabajo.

PALABRAS CLAVE: Relaciones humanas; Salud; Enfermería.

${ }^{1}$ Enfermeira. Especialista em Administração Hospitalar e Auditoria e Gestão em Saúde. Universidade Tuiuti do Paraná-UTP. ${ }^{2}$ Enfermeira. Doutora em Enfermagem. Orientadora de monografia do Curso de Especialização em Auditoria e Gestão em Saúde UTP. ${ }^{3}$ Enfermeira.Mestre. Coordenadora do Curso de Especialização em Auditoria e Gestão em Saúde. Docente do Curso de Graduação da UTP

Autor Correspondente:

Ana Maria Dyniewicz

Rua Padre Anchieta, 1965 - 80730-000 - Curitiba-PR

Recebido: 10/04/07

E-mail: anadyni@netbank.com.br 


\section{INTRODUÇÃO}

O ambiente de trabalho é constituído de estrutura física que confere base para a estrutura social, ambas influenciam o comportamento das pessoas que nele interagem e, por conseguinte, nos resultados de empresas em todos os sentidos. Como o ser humano é, também, fruto do meio em que vive e gerido por necessidades básicas como a alimentação, o sono, a atividade física, a segurança, a participação, a autoconfiança, a afeição, essas e outras necessidades podem motivá-lo ou não. Quando não satisfeitas são motivadoras de comportamentos que podem levar à desorganização, à agressividade, à reações emocionais diversas como alienação e apatia, sejam nas suas relações pessoais como profissionais.

O trabalho é a forma como o homem interage e transforma o ambiente, assegurando sua sobrevivência e tendo nas relações interpessoais mais uma maneira de contribuir para que tal aconteça. Contudo, as pessoas têm objetivos diferenciados, e priorizam às vezes o que melhor lhes convém, em contraste com propósitos coletivos de serviços e instituições. Tal afirmação se direciona para a compreensão de que o ser humano reage de forma única e individual às situações, as quais vão assumindo a tonalidade predominante nas relações pessoais no trabalho.

Nas relações humanas, em especial com profissionais de diferentes áreas de conhecimento acadêmico exige-se, antes de tudo, trabalhar com os aspectos humanísticos de cada indivíduo envolvido em processo coletivo. Logo, a abordagem interdisciplinar demanda postura pessoal e, vale dizer que inclui padrões cultural-afetivos dos sujeitos envolvidos ${ }^{(1)}$.

Assim, percebe-se que não somente a técnica capacita o profissional a exercer as atividades para as quais a academia os preparou. É necessário, também, que os padrões comportamentais pessoais estejam em consonância com os propósitos do trabalho para o efetivo relacionamento com os demais profissionais, a fim de oferecer tratamento eficiente e eficaz aos pacientes.

Por outro lado, os esforços individuais no ambiente de trabalho não são suficientes para se obter êxito, é preciso ir além, compreender e aplicar os princípios da ética e das relações humanas.

A enfermagem, como corpo das instituições de saúde, influencia e é influenciada pelas mais diversas áreas: administrativa, serviço de apoio diagnóstico e tratamento, centros cirúrgicos, unidades de terapia intensiva, berçários, demais alas, fisioterapia, nutrição, lavanderia, equipe médica e outras. Por esse motivo, acredita-se que sejam os profissionais mais flexíveis quanto à realização de trabalho em equipe, visto que desde a concepção da profissão tem-se consciência que de sua atividade depende de toda a equipe de saúde.

Considerando, que relação humana é um termo utilizado para descrever as maneiras como administradores se relacionam com os trabalhadores é interessante conhecer como se dão essas relações e suas interfaces sociais e psicológicas. Assim neste artigo tem-se o objetivo de realizar uma reflexão sobre as tendências das relações interpessoais em instituições de saúde.

\section{RELAÇÕES INTERPESSOAIS}

João amava Teresa que amava Raimundo

Que amava Maria que amava Joaquim que amava Lili Que não amava ninguém.

João foi para os Estados Unidos, Teresa para o convento, Raimundo morreu de desastre, Maria ficou para tia, Joaquim suicidou-se e Lili casou com J. Pinto Fernandes Que não tinha entrado na história.

\section{Carlos Drummond de Andrade}

O poema trata da dinâmica das relações afetivas que é própria da natureza humana, nas quais evidenciase os constantes encontros e desencontros que caracterizam a adaptação diária nos relacionamentos. $\mathrm{Na}$ perspectiva profissional, as relações humanas acontecem no ambiente de trabalho, nele o trabalho humano é cercado por consciência e intencionalidade, designado por esforço planejado e coletivo. Nesse esforço o ser humano desenvolve características de relacionamento que o leva a se sentir responsável por si e pelos outros. Dessa forma, durante sua trajetória o ser humano nunca se encontra sozinho, por mais que seus relacionamentos possam ser superficiais( ${ }^{(2)}$.

Contudo, para a formação do ambiente favorável ao relacionamento, pode-se dizer que na comunicação, em todas as suas formas, tem-se a compreensão do outro em sua totalidade, transformando a experiência de vida em momentos de mudanças. Mudanças, que em ambientes organizacionais, foram ocorrendo diante de necessidades advindas da globalização.

Caracterizada por um ambiente estável, na Era Industrial as atividades predominantes eram as mecânicas e burocráticas, hierarquicamente delimitadas. Atualmente, na Era da Informação, as organizações se tornaram orgânicas e flexíveis, pois o ambiente organizacional é mutável, os níveis 
hierárquicos são reduzidos, há descentralização de poder e autoridade e as pessoas inseridas nessas organizações possuem cargos que sofrem mudanças, necessitam de autocontrole e direcionamento, favorecendo a execução de tarefas cada vez mais complexas e diferenciadas ${ }^{(3-4)}$.

Salienta-se as características do ser humano nessa nova era ${ }^{(4)}$ : $O$ homem é pró-ativo: visto que é orientado/motivado a satisfazer suas necessidades pessoais para alcançar seus objetivos e aspirações. $O$ homem é social: os relacionamentos ocorrem para obtenção de informações sobre si mesmos, sobre os outros e sobre o ambiente no qual o grupo está inserido. $O$ homem tem diferentes necessidades: as necessidades são alteradas constantemente fato que determina o valor e quantifica a motivação a cada ação/atitude. O homem percebe e avalia: o ser humano reconhece suas experiências e as avalia de acordo com suas experiências passadas, determinandoas em função de suas necessidades e valores, podendo ou não submeter seu julgamento à percepções distorcidas de acordo com suas necessidades no momento da avaliação. $O$ homem pensa e escolhe: pois há busca constante no sentido de alcançar seus objetivos individuais. O homem tem limitada capacidade de resposta: as pessoas não são capazes de se comportar de todas as formas, sejam elas físicas ou mentais, pois existem as diferenças individuais.

Com base nessas afirmações pode-se dizer que, inseridos em grupo, os indivíduos passam a executar sua atividade fim sob as características de cada um, tornando cada grupo único em função de seus componentes.

Não se pode deixar de evidenciar que as características dos indivíduos são decorrentes dos valores adquiridos pelas experiências vivenciadas, e que valores influenciam suas atitudes e comportamento. Como tal, é imprescindível a percepção dos valores individuais para a adequação das atividades a determinado grupo, pois esse fato pode comprometer o desenvolvimento e alcance das metas determinadas pela organização. Embora os valores sejam preferências individuais, as pessoas tendem a compartilhá-los dentro das culturas e das organizações ${ }^{(4)}$. Esse compartilhamento se dá por meio do trabalho em equipe.

A literatura expressa diferença entre trabalho em equipe e trabalho em grupo. Enquanto no grupo os componentes executam cada um separadamente as tarefas que lhe foram designadas, responsabilizandose isoladamente pelas ações, na equipe todos trabalham em uníssono, envolvidos cada um na tarefa de todos. Dessa maneira há comprometimento total para os resultados gerais ${ }^{(5)}$.

Na área da saúde este tem sido um grande desafio, entre outras razões, pela complexidade e condições de trabalho em instituições de saúde, contudo o que se espera dos profissionais em equipe é a participação no processo coletivo, estar comprometido consigo e com os demais profissionais promovendo troca de idéias, discutindo e aprendendo, proporcionando crescimento em conjunto ${ }^{(6)}$.

Incontestavelmente, para que aconteça o trabalho em equipe é preciso ter em mente que os seres humanos não funcionam à feição de máquinas isoladas dispostas lado a lado. A interação entre eles afeta o funcionamento de cada um e de todos, alterando assim o que poderia constituir o 'desempenho previsto ou esperado’ individual ou coletivo. Assim, o que se passa no relativo ao sócio-emocional do grupo não depende somente da inteligência, da competência e da qualificação técnica de seus membros, embora seja de vital importância para o alcance dos objetivos e obtenção de resultados com qualidade ${ }^{(7: 29)}$.

É possível afirmar, que a capacitação para o trabalho profissional acontece desde o momento em que o ser humano começa a se relacionar com o mundo, com as outras pessoas. Essa capacitação necessita de competência técnica e competência interpessoal. A competência técnica é aquela adquirida por meio de cursos, treinamentos, seminários, experiências e outros. A competência interpessoal é a habilidade de lidar com outras pessoas de forma adequada às necessidades de cada uma e às exigências da situação ${ }^{(8-9)}$.

Com essas características é possível perceber quanto é complexo o comportamento entre pessoas, há inferências ou suposições sobre suas motivações, intenções, personalidades, emoções e assim por diante, as quais se tornam determinante significativo de interações entre indivíduos. Essa reflexão sobre ambiente e pessoas pressupõe que a base para a solução eficaz de problemas, comunicação e outras atividades organizacionais e gerenciais, bem como das relações no trabalho, é a percepção do ambiente tal qual se apresenta e das pessoas inseridas no contexto.

Os conceitos aqui expressos de forma breve mostram, em síntese, que as pessoas influenciam e são influenciadas pelo ambiente trabalho, manifestando comportamentos compatíveis ou não ao alcance dos objetivos e metas estabelecidos pela instituição. Cabe aos gestores de serviços e instituições aprofundar 
conhecimentos sobre as relações interpessoais, auxiliando-os na tomada de decisão, para manter equipes de trabalho, sob o foco de objetivos e metas que desejam alcançar.

\section{RELACIONAMENTO HUMANO NA SAÚDE}

Percebendo o mundo cada vez mais globalizado e com necessidades de reformulações estratégicas para aumento na produtividade. Destaca-se a exigência cada vez maior dos trabalhadores de saúde em obter capacitação além de técnico-científica, tais como flexibilidade intelectual, gerenciamento e gestão, dimensionamento ético-político, comunicação e competência interpessoal. O desenvolvimento das competências interpessoais ainda não é devidamente estimulado pelas organizações e parte principalmente do interesse pessoal de cada indivíduo ${ }^{(10)}$.

Também, as instituições que prestam assistência em saúde, formadas por diversos profissionais, em sua maioria não promovem reflexões sobre os processos de trabalho em saúde, pois entre outros fatores as regras, as normas e as rotinas facilitam o distanciamento dos trabalhadores em saúde dos objetivos fundamentais do seu existir ${ }^{(2)}$. A sociedade, em conseqüência, não tem acesso a essas informações e não dispõe de mecanismos de controle sobre tais entidades.

Esse momento é chamado de diferentes moralidades, ou seja, a presença de diferentes valores e conhecimentos tidos como verdadeiros e que emergem em situações de conflito ${ }^{(11)}$, embora, é claro, o conflito seja inevitável nas organizações, obter resultados construtivos ao final desse processo é fundamental para o sucesso da organização ${ }^{(4)}$. Por isso, é de vital importância repensar os processos que envolvem a prestação de serviço e formação de profissionais abertos às mudanças e às inovações. Dentre os processos está o desenvolvimento da capacidade de utilizar recursos racionais ou subjetivos que cada ação exige do indivíduo, responsabilizando-se pela atitude tomada. Contudo, pode ocorrer o individualismo e, conseqüentemente, a competitividade entre as relações sociais, promovendo os conflitos interpessoais ${ }^{(10)}$.

Em outro aspecto, ressalta-se a importância das relações humanas no trabalho para a busca do prazer e satisfação, pois uma atividade que não se revela interessante torna-se sem sentido, desmotivante e relações superficiais ${ }^{(12)}$. Em especial, a realização do trabalho na área da saúde deve acontecer de forma integral, participativa, não tendo como objetivo único a normalização e ordenação das ações. Os trabalhadores devem ser participantes de todo processo e, fundamentalmente, com suas necessidades humanas atendidas ${ }^{(13)}$.

\section{RELACIONAMENTO HUMANO NA ENFERMAGEM}

Os profissionais de saúde, no desenvolvimento de suas atividades diárias, utilizam-se de conhecimento científico, valores, habilidades e atitudes que devem ser empregados na busca da melhoria da condição humana no processo de vida ${ }^{(10)}$. Porém, observa-se na equipe de Enfermagem, que o paciente ainda está inserido em ambiente em que a especialização e a técnica são soberanas. Por esse motivo, o trabalhador de enfermagem não consegue perceber o todo que envolve este ser, mesmo que suas ações sejam tomadas a fim de promover, manter ou recuperar a saúde ${ }^{(2)}$.

Além do mais, os resultados apresentados pelos pacientes em resposta aos cuidados de enfermagem são difíceis de serem identificados, considerando-se que é complexo separar o resultado das intervenções de enfermagem das demais intervenções multiprofissionais ${ }^{(14)}$.

Para os enfermeiros as ações de interdependência, colaboração e articulação com os demais profissionais tornam-se parte da prática administrativa, pois a enfermagem é uma atividade concreta e produtiva, mas que em função da estrutura hospitalar assume diversas atividades além daquelas inerentes à profissão ${ }^{(15)}$.

Deveria haver, em âmbito institucional processos de trabalho vinculados à produção de cuidados de enfermagem em quantidade e qualidade adequadas, desempenhados por uma equipe em contínuo processo de auto e heteroavaliação, reordenados segundo os princípios emanados da educação continuada, organizados como um todo ${ }^{(14)}$. Em relação à equipe de enfermagem, como trabalhadores na prestação de serviços de saúde e responsáveis por essa produção de cuidados haveria necessidade de maior atenção à sua saúde, melhores condições de trabalho e de proteção à vida.

Outra peculiaridade entre os trabalhadores de enfermagem é de acreditarem na potencialidade de saúde de seus pacientes, transferindo a estes suas crenças, valores e sentimentos, buscando realizar sua atividade transcendendo a técnica, com a finalidade de uma recuperação além da fisiológica. Por esse 
motivo pode-se afirmar que o processo comunicacional torna-se essencial por meio do toque, do olhar, dos sinais e do silêncio ${ }^{(2)}$.

Atualmente, a inserção dos trabalhadores de enfermagem em cenário mutável, complexo, instável e cheio de contradições com as instituições hospitalares, exige a efetiva gestão desses recursos humanos com responsabilidade, criatividade e liderança. Dessa forma, gerenciar significa desenvolver talentos, incentivar a criatividade, apoiar a participação, estimular inovações, com ética e respeito ao outro ${ }^{(16)}$.

Essa identificação pode ocorrer por meio de avaliação de desempenho como um sistema para a apreciação do indivíduo na função que ocupa e para avaliar seu potencial de desenvolvimento. A avaliação tem, portanto, como finalidade, detectar o nível de capacitação ou qualificação profissional, analisando-o e correlacionando-o face aos objetivos da empresa. No entanto, os seus objetivos terão que expressar com clareza o seu significado para a empresa e a sua utilização como ferramenta gerencial para administrar o desempenho. Destacando-se que resultados individuais estão se descaracterizando e dando lugar às ações de grupo, pois os resultados são decorrentes de contribuições compartilhadas ${ }^{(16)}$.

Dessas inferências, enfatiza-se o atributo da condição humana em ser eminentemente social. Os enfermeiros, por condição própria do trabalho, estão inseridos em serviços de saúde como estruturas sociais complexas, em interrelações que são próprias da nossa cultura, ora de maior ora de menor valorização profissional, afetiva e espiritual. Mas, o desenvolvimento da ciência e tecnologia em prol da assistência em saúde é projeto coletivo o qual requer partilha e maximização de ações de impacto para o bem.

Trata-se de romper com a crise da consciência dos valores por recuperação da auto-compreensão do ser humano como pessoa ontologicamente fundada e o seu intrínseco e eminente valor. Valores que são dimensões que identificam o ser-pessoa como a subjetividade, a vontade livre, a linguagem, a sociabilidade, a cultura, o trabalho e a técnica ${ }^{(17)}$.

\section{CONSIDERAÇÕES FINAIS}

A interdependência do indivíduo com a organização é imensa, visto que o primeiro possui suas motivações individuais e a segunda, as necessidades de alcance de objetivos e metas, tornando-os indissociáveis.

O hospital, como as demais instituições de saúde, é um universo que contém complexidades, diferentemente do resto das organizações. De acordo com a literatura e com experiências vivenciadas em instituições de saúde, o relacionamento humano no setor saúde, é influenciado pelas pessoas, ambiente, condições de trabalho, infra-estrutura e outros aspectos, principalmente quando inseridos no multifacetado e dinâmico espaço hospitalar.

Nesse ambiente, desde a admissão do paciente até a alta, há etapas que exigem intervenções. Nelas, toda a equipe de saúde deve implementar conhecimento, desenvolver habilidades, manter a ética para a sofisticação da assistência à saúde, no entanto, isso tudo dependerá de relações humanas, imprescindíveis para a realização de sua atividade fim.

Contudo, no processo de trabalho de enfermagem se esquece do corpo individual do trabalhador, em função da execução das atividades dentro de normas e rotinas. Em sua composição são encontrados diferentes formações e diferentes níveis culturais, nem sempre respeitados ${ }^{(13)}$.

Pensar em enfermagem significa pensar no cotidiano da profissão, o viver no emaranhado das relações necessárias para o desenvolvimento das ações, viver situações que confrontam a fragilidade da vida constantemente, fatos que levam ao sofrimento do corpo, apreensão e angústia, fazem com que os envolvidos com o cuidado apliquem muita energia, paixão e investimento pessoal. No entanto, essas situações podem acarretar em desestabilização do ser, levando-o ao sofrimento ${ }^{(18)}$.

É fato que a instituição não deve se distanciar de seus objetivos principais, de suas metas, mas deve adotar condutas com a participação das equipes, tornando-se cada vez menos burocrática e cada vez mais participativa ${ }^{(13)}$. Logo, para o efetivo gerenciamento dos recursos humanos dentro da enfermagem é fundamental a percepção de sentimentos que são desencadeados pelas pessoas que compõem a equipe, pois quanto melhores forem as relações internas, mais harmonioso torna-se o ambiente de trabalho e conseqüentemente, mais efetivo.

Propõe-se para finalizar que haja em todas e quaisquer relações interpessoais a prática da arte do diálogo por meio de algumas ações ${ }^{(19)}$ : a linguagem como principal forma de comunicação e transmissão do conhecimento, idéias, crenças e até emoções. Sua expressão no processo do relacionamento social é determinante e ocorre em gentileza, pois a forma como se fala algo a alguém, traz sempre resultados 
compatíveis à sua natureza; o convívio coletivo para garantir a saúde do grupo e enriquecer, sobremaneira, o indivíduo que se dispõe a dedicar-se a ele, seja em encontros formais ou informais; a conversa como meio para se fazer entender. Facilita as relações interpessoais, seja ela técnica, acadêmica, social, não importa, é a conversa que cria o elo que ativa a sociabilidade.

\section{REFERÊNCIAS}

1. Patrício ZM. Administrar é trabalhar com gente. Texto Contexto Enferm. 1996;5(2):55-77.

2. Souza LNA, Padilha MICS. A comunicação e o processo de trabalho em enfermagem. Texto Contexto Enferm. 2002;11(1):11-30.

3. Chiavenato I. Gestão de Pessoas: e o novo papel dos recursos humanos nas organizações. $2^{\mathrm{a}}$ ed. Rio de Janeiro: Elsevier; 2004.

4. Schermerhorn JR, Hunt JG, Osborn RN. Fundamentos de comportamento organizacional. $2^{\mathrm{a}}$ ed. Porto Alegre: Bookman; 1999.

5. Monteiro JK, Ribeiro E, Souza FP, Serafim SM. Habilidade para trabalhar em equipe. Aletheia. 2002;16:7-14.

6. Olinski SR, Lacerda MR. As diferentes faces do ambiente de trabalho em saúde. Cogitare Enferm. 2004;9(2):43-52

7. Moscovici F. Equipes dão certo. $5^{\mathrm{a}}$ ed. Rio de Janeiro: José Olimpio; 1999.

8. Moscovici F. Desenvolvimento Interpessoal. $7^{\mathrm{a}}$ ed. Rio de Janeiro: José Olimpio; 1997.

9. Vieira EMF, Pacheco RCS, Rodrigues RSO. Enfoque cognitivo e o uso das tecnologias de informação em situação de limitação sensorial. Rev Dial Educac. 2004;4(12): 65-78.

10. Fernandes JD, Araújo FA, Fernandes J, Reis L, Gusmão MCM, Santana N. Competência interpessoal nas práticas em saúde: o individual e o coletivo organizacional. Texto Contexto Enferm. 2003;12(2):210-5.

11. Oliveira MLC, Guilhem D. O agir ético na prática profissional cotidiana das enfermeiras. Rev Bras Enferm. 2001;54(1):63-73.

12. Santos KMAB, Silva MJP. Comunicação entre líderes e liderados: visão dos enfermeiros. Rev Esc Enferm USP.
2003;37(2):97-108.

13. Martins JJ, Faria EM. O cotidiano do trabalho da enfermagem em UTI: prazer e sofrimento. Texto Contexto Enferm. 2002;11(1):222-43.

14. Cianciarullo TI. C e Q: Teoria e prática em auditoria de Cuidados. São Paulo: Ícone; 1997.

15. Gindri L, Medeiros HMF, Zamberlan C, Costenaro RGS. A percepção dos profissionais da equipe de enfermagem sobre o trabalho dos enfermeiros. Cogitare Enferm. 2005;10(1):34-41.

16. Leite MMJ, Gualda DMR, Gonçalves VLM, Fugulin FMT, Castilho V, Ortiz DCF et al. Análise do instrumento utilizado o processo de avaliação de desempenho da equipe de enfermagem do hospital universitário da USP. Rev Esc Enferm USP. 1999;33(3):265-78.

17. Silva PC Antropologia da pessoa humana. Disponível em: www.lo.unisal.br/sistemas/bioetica/arquivos/. Acesso em: 20 out. 2007.

18. Gonzales RMB, Beck CLC. O sofrimento e o prazer no cotidiano dos trabalhadores da enfermagem. Texto e Contexto Enferm. 2002;11(1):169-86

19. Loureiro PC. Relações interpessoais e sociabilidade. Disponível em:<http://recantodasletras.uol.com.br/ artigos/164899>. Acesso em: 22 out.2007. 